\title{
La conservación de bienes culturales muebles en El Salvador: Una tarea por hacer
}

Beatriz Castillo

La conservación y restauración ha tomado un lugar preponderante para la cultura en todo el mundo. "Desde la antigüedad, y más específicamente desde la época medieval, el renacimiento o el barroco, se aplicaban prácticas para la conservación de edificios, pinturas murales, esculturas y pinturas con un enfoque de prevención del deterioro" ${ }^{1}$.

La institución responsable de recolectar, estudiar, conservar y exhibir el patrimonio cultural que forma sus colecciones es el museo, en cualquiera de sus expresiones.

La actividad de mayor responsabilidad que se deriva es la conservación, ya que sin obras en buen estado no existen materiales para exhibir.

Esta es una actividad que a través del tiempo se ha convertido en una profesión científica que se dedica a mantener vivas las obras de arte, monumentos y bienes muebles que forman parte del acervo cultural de una nación o cultura.

La restauración formal tiene sus inicios en Europa y sus criterios influenciaron de gran manera la restauración en América.

Sin embargo hay evidencias que en el pasado se realizaron intervenciones de restauración principalmente en objetos utilitarios. Estas restauraciones se llevaron a cabo uniendo fragmentos de cerámica con paja, y fibras naturales; también por amarrado, haciendo perforaciones y luego pasando los hilos.

1 Koller, M. (1994): Learning from the History of Preventive Conservation. Preventive Conservation, Practice, Theory and Research. IIC Ottawa Congress, 12-16 September 1994. 
Esto nos permite saber que cada región desarrolló sus técnicas particulares de acuerdo a sus recursos y medio ambiente en el que se encontraban.

En El Salvador la conservación de bienes culturales muebles es un área poco conocida y de reciente creación, pero importante para el bienestar de nuestro acervo cultural. Es por ello que los especialistas de la materia tenemos el compromiso de transmitir los conocimientos que contribuyan a la conservación de nuestro patrimonio.

Es necesario que la población tenga conocimiento de qué es el patrimonio cultural, y que se apropie de él y esté consciente de la importancia de conservarlo, ya que este será el legado cultural para las futuras generaciones, permitiendo de esta manera conocer nuestro origen; quienes somos, de dónde venimos, el porqué de la forma de nuestro pensamiento.

Para ello es importante definir los conceptos que están relacionados en la conservación y restauración de los bienes culturales. En primer lugar se puede decir que patrimonio cultural se entiende como: el conjunto de Bienes Culturales producto del intelecto humano a través del tiempo, abarcando sus expresiones del pasado y presente.

En el mundo existen instituciones como International Council Of Museums (ICOM) que definen los conceptos como:

\section{Conservación}

Que son 'Todas aquellas medidas o acciones que tengan como objetivo la salvaguarda del patrimonio cultural tangible, asegurando su accesibilidad a generaciones presentes y futuras' 2 .

Inmersas en ella se encuentra la conservación preventiva, curativa y la restauración, las que nos indican el respeto al significado y las propiedades físicas del bien cultural que se está estudiando.

2 Terminología ICOM-CC. Resolución que se presentó a los miembros del ICOM-CC durante la XV Conferencia Trianual. Nueva Delhi, 22-26 de Septiembre de 2008. 


\section{La conservación preventiva}

Trata sobre "Todas las medidas y acciones que tengan como objetivo evitar o minimizar futuros deterioros o pérdidas" 3 . Como ejemplo mencionamos evitar que el sol llegue directamente sobre los objetos, colocarlos en lugares de donde no se caigan con ningún movimiento, adecuar el sistema de vigilancia para evitar el vandalismo.

La conservación preventiva ha sufrido cambios de fondo, en épocas pasadas se trataban objetos en forma personalizada, actualmente se piensa en colecciones; en tiempos pasados se corregían daños en la sala, ahora se debe pensar en el edificio; el tratamiento particularizado nos llevaba semanas, en esos tiempos se piensa en que las medidas se llevarán por años; la persona, se ha transformado en grupo o equipo; lo que se consideraba un gasto inmediato, se ha modificado por una inversión a largo plazo; la programación a un año se ha convertido en programas amplios.

Estas medidas y acciones no interfieren con los materiales y la estructura física de los bienes y no modifican su apariencia.

Otros aspectos importantes a tomarse en cuenta en la conservación preventiva es la realización adecuada de embalajes, transportes, manipulaciones, almacenajes, préstamos interinstitucionales, exposiciones de bienes muebles, mantenimiento y control de los factores de deterioro ambiental como: la luz, la humedad, contaminación atmosférica e insectos. Y como una alternativa conservadora puede incluirse la producción de réplicas con el fin de preservar los originales.

En este sentido, el Comité para la Conservación del ICOM (International Council Of Museums), ha modificado la estructura de sus grupos de trabajo creando el grupo de "Conservación Preventiva". Que envuelve a los elementos como "Iluminación y Control Climático", "Control del Biodeterioro" y "Protección de Obras de Arte durante su Transporte". Sin embargo las funciones siguen desarrollándose"4.

\footnotetext{
3 Ídem.

4 ICOM Committee for Conservation (1996): 11th Triennial Meeting. Edinburgh, 1-6 September, 1996.
} 


\section{Restauración}

Son "Todas aquellas acciones aplicadas de manera directa sobre un bien o un grupo de bienes culturales que tengan como objetivo detener los procesos dañinos presentes o reforzar su estructura. Estas acciones sólo se realizan cuando los bienes se encuentran en un estado de fragilidad notable o se están deteriorando a un ritmo acelerado, por lo que podrían perderse en un tiempo relativamente breve" 5 .

Como ejemplo tenemos la desinfección de maderas, la desalinización de cerámicas, estabilización de metales corroídos, consolidación de pinturas murales, entre otros.

Los factores de deterioro son un aspecto muy importante que se debe tener presente ya que de esta manera protegeremos adecuadamente los bienes culturales. Estos se dividen en "Factores Externos o extrínsecos" y "Factores Internos o Intrínsecos" y se deben tomar en cuenta desde el momento de elaboración de un objeto, porque cuando se inicia una transformación que puede desembocar en la pérdida total, esto se debe a que todos los materiales por su naturaleza o composición tienden a degradarse. Otros contaminantes interiores son los que provienen de los muebles y vitrinas, que se desprenden de las maderas, pinturas, adhesivos.

Además los cambios provocados por las condiciones climáticas que diaria y estacionalmente modifican la relación de contaminantes ambientales, temperatura, precipitación pluvial, vientos dominantes, la flora y la fauna características del lugar, actividades humanas en el contorno de las piezas, insolación, fuentes de iluminación, contaminantes producidos por los combustibles, siendo estos factores extrínsecos; conocidos como factores físicos, químicos y biológicos de deterioro para los materiales. Este último causado por una serie de seres vivos como bacterias, hongos, líquenes, plantas superiores, insectos, roedores, etc. Aunque el principal daño es producido por la acción del hombre consciente o inconscientemente.

También existen otros factores físicos externos denominados mecánicos como la manipulación inadecuada, choques, caídas y vibraciones, estos son movimientos causados por el tráfico cercano, el paso de visitantes, maquinaria

5 Ibíd. 
(ascensores, sistemas de climatización, extractores, etc.) causan micro fisuras en las obras, por fatiga del material; choques o roces de los objetos entre sí o con el capelo o vitrina. Inclusive en el edificio.

El monitoreo y análisis de los contaminantes provenientes del exterior incluye a los óxidos de nitrógeno, ozono, dióxido de azufre, partículas suspendidas y otros oxidantes fotoquímicos (oxidaciones producidas por la presencia de la luz), Los motores de combustión interna producen micro-partículas de carbón que constituyen un problema grave de contaminación y suciedad que se limpia con dificultad y causa deterioro a las piezas tratadas.

Los edificios que usan sistemas de aire acondicionado deben extremar el mantenimiento y limpieza de éste, para evitar la formación de contaminaciones biológicas, suciedad, óxidos metálicos, etc. en los conductos que serían propagados por el sistema.

Estos datos permiten a los conservadores de museos proyectar sus estrategias de conservación preventiva. Ciertos oxidantes producidos por la presencia de la luz son perjudiciales a una gran cantidad de colorantes orgánicos. Los metales y las conchas marinas se ven afectadas por los ácidos y gases producidos por los materiales de construcción de los muebles. El vidrio y los barnices de la cerámica no son sensibles a este contaminante.

Se pueden aplicar métodos sencillos y económicos para detener la acción de estas impurezas como son filtración del aire, colocación de recipientes planos con material absorbente en el interior de las vitrinas. Otra solución más compleja es identificar, aislar y eliminar el material que genera el contaminante.

Actualmente es práctica normal cuidar que las condiciones de humedad, temperatura e iluminación sean adecuadas para que los materiales no sufran deterioros; dependiendo de la naturaleza de los materiales de los objetos. Tomando en cuenta estas condiciones para conservar las colecciones las mencionamos a continuación:

\section{Humedad}

Cada uno de los objetos tiene por su composición material una cantidad propia de humedad interna. "Lo más importante es evitar los cambios bruscos en sus valores de subida por encima de $65 \%$ ya que se favorecería el ataque 
biológico o la caída por debajo de 30\%, que eliminaría parte del agua constituyente de los materiales orgánicos" ". Con estos niveles de Humedad Relativa debemos prestar especial atención a los objetos metálicos que pueden presentar procesos de corrosión activa. Es por ello que la utilización de agentes desecantes (gel de sílice o disoluciones saturadas, filtros de controladores ambientales, absorbentes de azufre, oxígeno, etc.), lacas o barnices anticorrosivo, capelos especiales para ellos, son los sistemas más utilizados.

\section{Iluminación y temperatura}

El efecto de las oxidaciones producidas por la presencia de la luz y altas temperaturas son dos factores de deterioro relacionados con la iluminación, ya que "estas aceleran las reacciones químicas como oxidación, hidrólisis, decoloración, fotólisis etc. Otra manifestación está dada por el daño térmico que ocasiona"7.

La elección de la fuente de luz y la forma de iluminar los objetos es de vital importancia ya que con el empleo de elementos como los filtros se nivela la radiación ultravioleta tan dañina para el material orgánico. Y se baja la temperatura que se genera afectando a los materiales con reblandecimiento de ceras, barnices, látex, gomas, etc. el efecto de valores altos o por debajo de temperaturas de congelación, produce fragilidad de los plásticos.

Otro factor importante son los desastres naturales: dentro de estos se consideran los daños provocados por terremotos, derrumbes, deslaves de tierra, huracanes, lluvias intensas, inundaciones. En zonas de alto riesgo se debe realizar un diseño arquitectónico resistente a todos los daños provocados por los desastres naturales ya mencionados, deben planearse las exhibiciones con un sistema especial para evitar el movimiento de las obras en el interior de las vitrinas, así como también el aseguramiento de las obras en la estantería de los depósitos para enfrentar los daños que de antemano se sabe que son muy posibles.

En zonas de bajo riesgo se recomienda contar con un plan de salvamento emergente para remediar supuestos imprevistos, así como los elementales

6 Chan, Julio. Conservación Preventiva. Documento inédito.

7 Plenderleith, H .J.; Philippot, P. Climatology and Conservation in Museums. Museum XIII. No 4. UNESCO, París. 1960. 
contra incendios, cortes de energía eléctrica, ruptura de instalaciones hidráulicas, vandalismo, robo, terrorismo, etc.

\section{Medidas para la conservación preventiva en los museos.}

Entre las acciones para la preservación de las obras que ingresan a un museo se encuentra la inspección y dictamen de las nuevas adquisiciones o prestamos. Se realiza una investigación y observación del bien cultural con el fin de constatar su estado general en el momento de su llegada a la institución, para determinar futuras acciones de preservación, conservación o restauración si es necesario.

Debe existir una zona de aislamiento, En caso de determinar la existencia de un ataque por xilófagos, antes de que el objeto adquirido pase al depósito o a la sala de exhibiciones, se someta a un período de aislamiento o cuarentena y desinsectación o desinfección del objeto que evite su propagación. Si fuera posible, la captura de algún insecto nos ayudaría a su identificación y determinación del ciclo biológico. En el caso de los microorganismos como los hongos y bacterias nos pueden ayudar la presencia de olor, cambio de color por aparición de manchas, aumento o cambios de color en ellas.

Una vez que el objeto es seguro para el resto de la colección puede ser estudiado, medido, fotografiado, etc. y para ello debe contarse con un lugar específico, fuera del depósito, las salas de exposición y las oficinas.

El personal que acceda a esta zona deberá comprometerse a cumplir una serie de normas y recomendaciones para el manejo y manipulación de los bienes, que deben exigirse también en el caso de préstamo temporal de los objetos. Las cuales van desde los límites de iluminación en la toma de fotografías, hasta la utilización de guantes, de algodón o polietileno, nunca de látex ya que estos pueden despedir partículas que se depositan en el objeto que al humedecerse pueden convertirse en acido sulfúrico que fácilmente desintegra el engobe; usar las dos manos al manipular los objetos, no utilizar las asas y otros elementos de riesgo propios de la pieza; solicitar ayuda con los objetos voluminosos o pesados; uso de contenedores, carritos de transporte y superficies de trabajo alfombradas; selección de los útiles de escritorio, como

6 Ibid., Págs. 207-208

7 Ibid., Pág. 208 
plumas, rotuladores libres de ácido, prohibición de tomar alimentos o bebidas, fumar; abrir ventanas, si las hay; introducir bolsas o paquetes; plantas o flores, barnices; retirar las envolturas de los objetos con cuidado para volver a usarlas; dejar las piezas como las encontramos, dentro de su embalaje, bolsa, estante, etc.

Los objetos que forman las colecciones no son adornos, ni curiosidades. Están bajo nuestra custodia, aunque sea de forma temporal y no son una propiedad particular nuestra. Nuestro trabajo debe ir dirigido a mantener su integridad física, ya que ésta es el vehículo transmisor de la información.

Desde su llegada al acervo o colección deben tener un lugar propio, ya sea en el depósito o en la sala de exhibición, pero no pueden estar dispersos por los pasillos o las mesas de los cubículos. Si hay que fotografiarlos, estudiarlos o restaurarlos se retiran del depósito o vitrina y se devuelven al acabar el proceso.

\section{El depósito y las Salas de exposición}

Por seguridad y para que el edificio actúe como aislante y amortiguador de preferencia estarán al interior. Con fáciles accesos para la llegada y movimiento interno de los objetos. En caso de acceso a la calle se dejará sin ventanas al exterior, se pondrá especial cuidado en los conductos de luz, agua, registros, cielos falsos, tarimas, etc.

La limpieza de estas áreas es fundamental para evitar crear un ambiente propicio para un ataque biológico y debería realizarse mediante aspiración, sin utilizar medios acuosos o productos de limpieza industrial que contengan amoníaco, sosa, ácido etc. que producen vapores perjudiciales para los bienes. Si se necesita pintar, utilizar pinturas libre de ácidos y azufre. Incluso existen o se preparan algunas pinturas, para zonas de registros o conductos interiores, con una dosis de insecticida.

Es importante controlar la entrada de partículas ambientales (polvo, hollín, etc.) utilizando filtros o instalando sistemas de presión positiva filtrada en salas, vitrinas y depósitos.

De esta manera contribuiremos a una conservación efectiva y consciente de la labor que debe realizarse tanto dentro de los museos como con colecciones 
particulares y acervo eclesiástico. Es de vital importancia el conocimiento de la conservación idónea de los bienes culturales ya que todos forman parte de nuestro acervo nacional.

\section{Referentes bibliográficos}

- Arbor. "Conservación del Patrimonio Artístico". Consejo Superior de Investigaciones Científicas. Revista. Madrid. Septiembre 1999, n CLXIV, 645.

- Cabrera, J. M. Conservación y Restauración. 50 Años de Protección del Patrimonio Histórico Artístico 1933-1983. Ministerio de Cultura, Madrid. 1987.

- Canadian Conservation Institute, Audiovisual Department, Université du Quebec a Montreal. PREVENTIVE CONSERVATION IN MUSEUMS. CCI Ottawa. 1995

- Caneva, G. Nugari, M.P.,Salvadori, O. La biología en la restauración. Editorial NEREA. S.A. junta de Andalucía. Consejería de Cultura IAPH. España, 2000.

- Chan, Julio. Conservación Preventiva. Documento inédito

- Hernández Gil, D. Datos Históricos sobre la Restauración de Monumentos. 50 Años de Protección del Patrimonio Histórico Artístico 1933-1983. Ministerio de Cultura, Madrid. 1987.

- ICOM Committee for Conservation. 11th Triennial Meeting. Edinburgh, 1-6 September, 1996.

- Koller, M. Learning from the History of Preventive Conservation. Preventive Conservation, Practice, Theory and Research. IIC Ottawa Congress, 12-16 September 1994.

- Michalsky, S. Relative Humidity: A Discussion of Correct/Incorrect Values. ICOM Committee for Conservation, 10th Triennial Meeting. Washington 22-27 August. 1993

- Museos Españoles. Datos estadísticos. Colección Datos Culturales No. 4. Secretaría General Técnica, Ministerio de Cultura. Madrid. 1995

- Terminología ICOM-CC. Resolución que se presentó a los miembros del ICOM-CC durante la XV Conferencia Trianual. Nueva Delhi, 22-26 de Septiembre de 2008. 


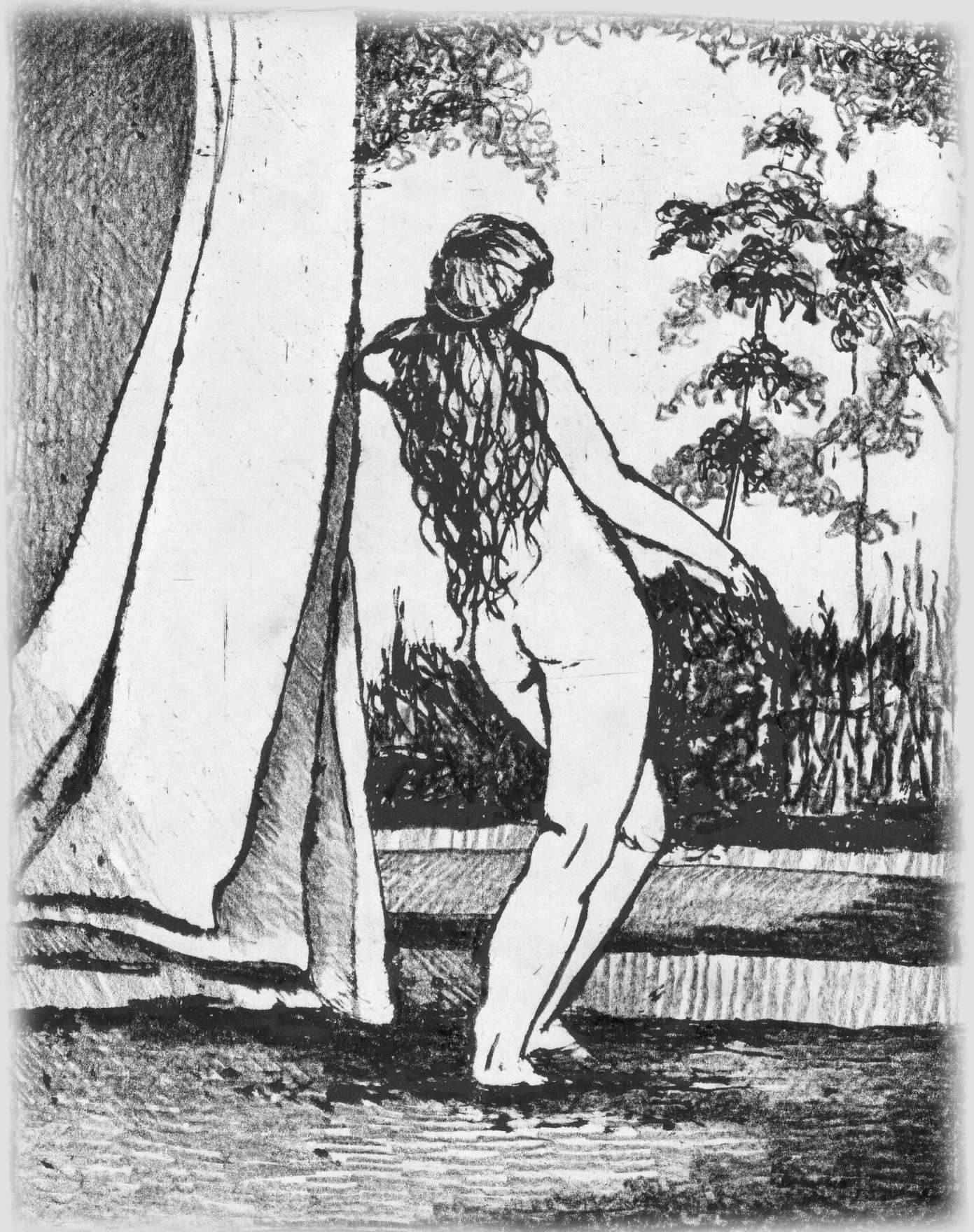

$$
\frac{\text { IVAN }}{\text { NAVAREJJE }}
$$

